\title{
A Comparative Study of Executive Functions and Cognitive Emotion Regulation in Patients with Borderline Personality Disorder and Normal Individuals
}

\author{
Majid Safarinia ${ }^{1}$, Hossein Zare ${ }^{2}$, Leila Ghasemifard Vashe ${ }^{3,}$, \\ Sajjad Vakilee Abasaliloo ${ }^{4}$ \\ ${ }^{1}$ Associate professor, Department of Psychology, Payame Noor University, PO BOX 19395 - 3697, \\ Tehran, IRAN \\ ${ }^{2}$ Professor, Department of Psychology, Payame Noor University, PO BOX 19395 - 3697, Tehran, \\ IRAN \\ ${ }^{3}$ General Psychology Graduate Student, Department of Psychology, Payame Noor University \\ overseas unit in Berlin, Germany. \\ ${ }^{4}$ MA, Department of Psychology, Tabriz University, Tabriz, Iran. \\ Corresponding e-mail: dghasemifard@yahoo.de
}

Key words: Cognitive Disorders, Emotional Processing, Mental Reaction, Borderline Personality Disorder.

ABSTRACT. The aim of this study was to compare the cognitive disorders, processing emotional stimulants and mental reaction in patients with borderline personality disorder and normal individuals. The study was descriptive and scientific-comparative. The study population included all patients with borderline personality disorder who were referred to psychiatric clinics in Tabriz. Among this population, 50 patients with borderline personality disorder were matched with 50 healthy individuals from the general population of the city, who had no history of mental illness, and their demographic variables such as age, sex, educational level and marital status. They were selected by a random sampling technique and had completed the questionnaires on cognitive emotion regulation, mental reaction and the Wisconsin Card Test. In order to analyze the data, the multivariate analysis of variance (MANOVA) was performed with SPSS version 20. Results showed that there is a significant difference between the two groups in preservation error and total error components, as well as the positive and negative components of cognitive regulation, and also in mental reaction ( $\mathrm{p}<0.001)$. According to the findings, it can be said that better and more complete understanding of personality disorders, particularly borderline personality disorder, provides more effective and more specialized intervention in the treatment and prevention of recurrence in patients with this disorder.

\section{INTRODUCTION}

World statistics show that the prevalence of personality disorders, particularly borderline personality disorder, is increasing and some institutions have reported rates of 5.9 percent for the normal population (Grantz, Tull \& Gunderson, 2008). Borderline personality disorder includes a cluster of signs and symptoms that can be determined by unstable behavior and impulsivity. Impulsivity is considered as the main and infrastructural core of this disorder (Lieb, Zanarini \& Linehan and Bauhaus, 2004) and also as the basic aspect in the understanding of its pathology (Paris, 2006; Paris, Weinberg \& Gunderson, 2007). Patients with borderline personality disorder (BPD) are located on the border between neurosis and psychosis and are marked with great emotion, mood, behavior and object relations instability. This disorder, outpatients (?) schizophrenia, is called "as if" personality of pseudoneurotic schizophrenia, psychotic character and emotionally unstable personality (Neal, Kring, Davison \& Johnson, 2007). 
In most studies of patients with borderline personality (BPD) it is found that these patients have deficits in executive functions (Kunert, Druecke \& Sass et al., 2003; Sprock, Rader \& Kendall et al., 2000).

Executive functions are generally said to be a set of necessary skills for independent and purposeful activity, including much higher levels of neuro-developmental functions, such as working memory, inhibitory control, organizing, and rescheduling. (quoted from Mohamadzadegan, 2014).

According to the studies of Hila Gvirts, Harari, Braw et al., (2012) which is entitled "Evaluation of executive function in patients with borderline personality disorder and a control group", it was found that patients with BPD, compared to the control group, showed disorder in executive function and, as Judd (2005) stated, neurological damages that may have a key role in the development of borderline personality traits (Dell, Osso, Berlin \& Serati et al., 2011; Fertuck, Lenzenweger \& Clarkin et al., 2006). Hence Ruocco (2005), referring to the disrupted functions of borderline personality disorder, describes many of the symptoms of borderline personality disorder as a result of damage to the relationship between the frontal cortex and other brain areas. In this regard, Mak \& Lam (2013), also in a study, reported that Frontolimbic structures and functional abnormalities are widely the infrastructure of anomaly in borderline personality disorder.

Studies also show that people with borderline personality disorder have problems in identifying, distinguishing and integrating emotions in themselves and others and, as a result, instead of effective behavior or confrontation, they resort to a wide range of inappropriate behaviors, such as impulsive behaviors or self-destruction (Conklin, Curtis, Katsanys et al., 2006; Sharp, Pane, Ha et al., 2011). The majority of problems seen in borderline cases are directly the result of disorder in emotional regulation or disorder in an attempt to adjust the intense emotional reactions.

In this sense, many self-destructive, impulsive or self-mutilating behaviors, which are a part of the symptoms of borderline personality disorder, may be the result of emotional dysregulation. So it can be said that the core of borderline personality disorder is a disorder of emotion regulation (Sanislow, Girlo \& Mcglashan, 2000). Patients with borderline personality disorder also suffer from anhedonia (Marissen, Arnold \& Franken, 2012) and in comparison to ordinary people have less positive emotional and cognitive experiences (Reed \& Zanirini, 2011). According to the results of Winter, Alzynga and Ashmal's (2014), study patients with borderline personality disorder, in the face of events and negative incidents, are more irritable than normal individuals. Also in a study, which is named "The emotional responses to (to what ??) induced by negative emotions in patients with borderline personality disorder"(2013), Feliu-Soler, Carlos Pascual, Soler et al.conclude that, in comparison to a control group, BPD patients have a low cortisol level and a higher SAA level and also these patients show a greater level of sensitivity to negative emotions. Pfaltz, Schumacher, Wilhelm et al., (2015) in a study concluded that patients with borderline personality disorder have slight emotion.

Based on the presented points, determining the difference in executive functions and cognitive emotion regulation between patients with borderline personality disorder and normal individuals, is the main issue in this research.

\section{METHODS}

This study, according to the method of data collection, is a descriptive (non-test) and scientificcomparative research. Also the following tools were used to collect data:

1. Cognitive Emotion Regulation Questionnaire: This questionnaire was invented by Garnefski, Kraaij \& Spinhoven (2001) to assess how people think after experiencing threatening or stressful life events and has 36 items which, based on the Likert rating scale, are ranged from 1 (never) to 5 (always). This questionnaire conceptually has four parts and forms nine distinct subscales, each showing a specific strategy out of various cognitive emotion regulation strategies . 
These strategies are: self-blame, blaming others, acceptance, focus on thought, positive refocusing, refocus on planning, positive reappraisal, putting into perspective and catastrophizing.

The score of each strategy is obtained through the sum of the scores given to each of its constituent parts and can be in a range of 4 to 20 .

In addition, strategies like self-blame, blaming others, focusing on behavior and catastrophizing, together make up "negative" strategies of emotion regulation and strategies like acceptance, refocus on planning, positive refocusing, positive reappraisal and putting in its rightful place together make up "positive" strategies of emotion regulation.

Reliability of "positive", "negative" and "total cognitive" strategies are obtained using Cronbach's alpha coefficient. They are respectively, 0.91, 0.87, 0.93 (Garnefski et al., 2001). As Yousefi (2003, quoting Vakilee Abasaliloo, 2003) reported that the reliability of the questionnaire in Iranian culture, in a sample of 15 to 25 years, (year old subjects??) is 0.82 , which is obtained by the use of Cronbach's alpha coefficient for "total cognitive".

In Yousefi's study (2003, quoting Vakilee Abasaliloo, 2003) the validity of the questionnaire was estimated through the correlation between the scores of negative strategies and the scores of anxiety and depression in a questionnaire with 28 items for general health (Goldberg \& Hillier, 1979). The obtained coefficients were respectively 0.35 and 0.37 . Both were significant at the level of $(\mathrm{P}<0.01)$.

2. Wisconsin Card Sorting Test: This test estimates the abstract ability and the change of cognitive strategies in response to environmental feedbacks (Cavallaro, Cavedini, Mistretta et al., 2003). The test consists of 64 dissimilar cards with different shapes (triangle, star, cross and circle) and different colors. For the test, four pattern cards are first placed in front of the participant. The examiner first considers color as the original category, without notifying the participant, and asks him to place the rest of the cards one by one (on?) the following four pattern cards. After each attempt, the participant is notified whether his placement is correct or not. If the participant can consecutively do 10 correct categories, the main category will be altered and the next will be shaped.

The change of category is performed just by changing the pattern of yes and no feedback. In this way, the last correct answer is wrong in the new category.

The next category is "number", and then the three categories are repeated in order. Whenever the participant can categorize 6 steps successfully, the test is stopped. The validity of this test for cognitive deficits following brain damage is reported as more than 0.86 (Lezak, 1995). The reliability of this test is evaluated as 0.83 based on the agreement coefficient of assessors (Spreen, 1991). In Iranian cases, by use of the retest method, it is reported as 0.85 (Naderi, 1994).

\section{POPULATION, SAMPLE AND SAMPLING METHOD}

Populations of this study are all patients with borderline personality disorder who referred to psychiatric clinics in Tabriz. Among this population, 50 patients with borderline personality disorder were matched with 50 healthy individuals from the general population of the city who have no history of mental illness and their demographic variables such as age, sex, educational level and marital status, who were selected by the technique of random sampling.

To do the study, after obtaining the consent of the relevant authorities and informed consent from the patient (and, if necessary, their relatives), demographic information such as age, educational level, marital status, and social and economical status of all individuals was collected. Then questions on how to complete the questionnaire were explained by experts to both groups and they were asked to respond freely to each of the questions and the test points.

It should be explained that patients with borderline personality disorder had received a diagnosis of borderline personality disorder by specialists and psychiatrists in psychiatric clinics. 


\section{FINDINGS}

According to the results, 62 percent of participants with borderline personality disorder (BPD) were female and 38 percent were male. In the normal group, 34 percent of participants were male and 66 percent were female. Most of the participants in both groups were between 30 to 40 years old. In addition, in the normal group, 34 percent of participants are single and 66 percent were married. Among participants with BPD, 36 percent were single and 64 percent were married.

Table 1. Descriptive Statistics of Mean (M) and Standard Deviation (SD) of Both Groups in Wisconsin Card Sorting Test and Cognitive Emotion Regulation

\begin{tabular}{cccccc}
\hline & Statistics & & \\
\hline & Component & BPD Group & $\begin{array}{c}\text { Normal } \\
\text { Group }\end{array}$ \\
\hline Variable & Preservation Error & 8.70 & 5.75 & 3.14 & 3.93 \\
\hline $\begin{array}{c}\text { Executive } \\
\text { Function }\end{array}$ & Total Error & 13.80 & 6.97 & 7.44 & 5.08 \\
\hline $\begin{array}{c}\text { Cognitive } \\
\text { Emotion } \\
\text { Regulation }\end{array}$ & $\begin{array}{c}\text { Positive Cognitive } \\
\text { Emotion Regulation } \\
\text { Negative Cognitive } \\
\text { Emotion Regulation }\end{array}$ & 35.20 & 7.65 & 61.28 & 13.36 \\
& $\begin{array}{c}\text { Total Cognitive Emotion } \\
\text { Regulation }\end{array}$ & 57.58 & 6.42 & 27.14 & 5.34 \\
\hline
\end{tabular}

To investigate the significant difference between these groups, initially the assumption of normal distribution of groups was evaluated, using the Kolmogorov-Smirnov test. The $\mathrm{Z}$ score test for both groups in tests of executive functions and cognitive emotion regulation was not significant. This means that there is not a significant difference between the distributions of these groups with normal distribution, so the assumption of normality exists (Table 2).

Table 2: The Results of Kolmogorov-Smirnov test for Both Groups in Wisconsin Card Sorting Test and Cognitive Emotion Regulation

\begin{tabular}{|c|c|c|}
\hline & Statistic & \\
\hline Kolmogorov-Smirnov test & $\mathbf{Z}$ & Significance \\
\hline Wisconsin Card (Total Error) & 0.856 & 0.456 \\
\hline Difficulty in Emotion Regulation (Total) & 0.769 & 0.596 \\
\hline
\end{tabular}

In addition to using analysis of variance, the assumption of the homogeneity of variance was evaluated, using the Leven test. According to the results, the default of homogeneity of variances in the Wisconsin Card Sorting Test, and the total cognitive emotion regulation and their components in both groups were confirmed. This test was not significant for at least one variable.

Table 3: The Results of Multivariate Analysis of Variance for Two Groups of People with Borderline Personality Disorder and Normal Subjects

\begin{tabular}{cccc}
\hline \multicolumn{2}{c}{ Statistics } & & \\
\hline Test Name & Value & F & Significance \\
Pylayy Effect & 0.91 & 188.94 & 0.0001 \\
Wilkes' Lambda & 0.09 & 188.94 & 0.0001 \\
Hetling Effect & 10.05 & 188.94 & 0.0001 \\
Largest Root & 10.05 & 188.94 & 0.0001 \\
\hline
\end{tabular}


Table 4: The Results of Analysis of Variance of Between-Group Effects for Two Groups of People with Borderline Personality Disorder and Normal Subjects

\begin{tabular}{|c|c|c|c|c|c|c|}
\hline \multirow[b]{2}{*}{$\begin{array}{c}\text { Independent } \\
\text { Variable }\end{array}$} & \multicolumn{6}{|c|}{ Statistics } \\
\hline & $\begin{array}{c}\text { Dependent } \\
\text { Variable }\end{array}$ & Total Squares & DF & $\begin{array}{l}\text { Mean of } \\
\text { Square }\end{array}$ & $\mathbf{F}$ & Significance \\
\hline \multirow{5}{*}{ Group } & $\begin{array}{c}\text { Preservation } \\
\text { Error }\end{array}$ & 772.84 & 1 & 772.84 & 31.76 & 0.0001 \\
\hline & Total Error & 1011.24 & 1 & 1011.24 & 28.08 & 0.0001 \\
\hline & $\begin{array}{c}\text { Positive } \\
\text { Cognitive } \\
\text { Regulation }\end{array}$ & 1700.16 & 1 & 1700.16 & 143.30 & 0.0001 \\
\hline & $\begin{array}{l}\text { Negative } \\
\text { Cognitive } \\
\text { Regulation }\end{array}$ & 2316.84 & 1 & 2316.84 & 663.36 & 0.0001 \\
\hline & $\begin{array}{c}\text { Total Cognitive } \\
\text { Regulation }\end{array}$ & 475.24 & 1 & 475.24 & 5.84 & 0.018 \\
\hline
\end{tabular}

As seen in Table 4, there is a statistically significant difference between the two groups of people with borderline personality disorder and the normal individuals for preservation error $(\mathrm{F}=31.76$, $\mathrm{P}=0.0001)$ and total error $(\mathrm{F}=28.08, \mathrm{P}=0.0001)$. In addition, between the two groups of people with borderline personality disorder and normal individuals, there is a statistically significant difference in properties of positive cognitive emotion regulation $(\mathrm{F}=143.30, \mathrm{P}=0.0001)$ and negative cognitive emotion regulation $(\mathrm{F}=663.36, \mathrm{P}=0.0001)$, and the total cognitive emotion regulation $(\mathrm{F}=5.84$, $\mathrm{P}=0.018)$.

\section{DISCUSSION AND CONCLUSION}

The aim of this study is to compare executive functions and cognitive emotion regulation in patients with borderline personality disorder and normal individuals.

According to the results, there was a statistically significant difference between groups of people with borderline personality disorder and normal individuals in preservation error and total error and characteristics of cognitive emotion regulation (positive and negative cognitive emotion regulation. This significance in "preservation error" and "total error" components is in favor of the average of people with borderline personality disorder. This means that people with borderline personality disorder in comparison to normal individuals have higher average scores in Wisconsin Card Test parameters.

These results are in line with the findings of other studies such as Hila Gvirts, Harari, Braw, et al., (2013) and Williams, Darus, Gravz, et al., (2015).

Also one of the other findings of the study is that in "negative cognitive emotion regulation" and "the total of cognitive emotion regulation" mean of scores is in favor of an average group of people with borderline personality disorder. That means individuals with borderline personality disorder in comparison to normal individuals have higher mean scores in these components. In addition, in "positive cognitive emotion regulation", the difference between the mean of two groups is in favor of the average with normal individuals. This means that normal individuals have higher mean scores in this component, so normal individuals use more positive emotion strategies.

The results of the study by Sharp, Pane, Ha et al., (2011) are in line with the findings of this study. That study showed that people with borderline personality disorder have problems in identifying, distinguishing and integrating emotions in themselves and others and, as a result, instead of effective behavior or confrontation, they resort to a wide range of inappropriate behaviors such as impulsive behavior or self-destruction. Also the results of this study are in line with the results of the studies by Feliu-Soler, Carlos Pascual, Soler, et al., (2013), Pfaltz, et al., (2015).

In explaining the results it can be said that, despite the different definitions and a wide range of difficulty in emotion regulation, BPD can be considered as a multi-dimensional structure 
including lack of awareness, understanding and acceptance of emotions, lack of access to adaptive strategies to mitigate intensity or emotional response time, and no tendency to experience psychological distress (Lurberg et al., 2010), which all can be considered the characteristics of borderline personality traits. In this regard, because cognitive impairment stands in relation with the manner of learning an overburden event, short-term memory capacity, loss of consciousness and diverted attention (Morton, 2010), dealing with negative events and experience of negative emotions affects the level of cognition and executive function and disrupts it. Therefore, due to the interference with emotional daily activities, cognitive impairment can lead to major problems, and their compensation can require a long time.

In this connection, Beck and Emery (1985; quoted Salehi, 2015) have emphasized that the main characteristic of mood disorders is the nature of cognitive processing. According to the "Baver" theory, the existence of mood congruent biases affects a wide range of cognitive functions that may disrupt or facilitate access to information. In a conclusion about the relationship between emotional disorders and cognitive disorders, it can be stated that explanatory models have been proposed separately, but all of them have a same prediction about the effects of cognition on the processing of emotional information and vice versa. Various theories suggest that all cognitive processes that are involved with information about the threat show the biases towards information relating to the emotional subjects. Each system of memory and cognition to store data requires encoding, storage and retrieval of information. In other words, people's problems occur in the experience of normal daily situations (such as forgetting names or misunderstanding instructions) that are related to the errors in control in the processing of information. In this regard Harnishfeger (1995, quoted Salehi, 2015) suggests that the problems associated with deterrent processing are partly responsible for cognitive failures. According to the stated subjects, the results of this study can be used to recognize people with borderline personality disorder and a variety of related cognitive and behavioral characteristics because better and more complete understanding of personality disorders, particularly borderline personality disorder, provides a more effective and more specialized intervention in the treatment and prevention of recurrence in patients with this disorder.

Finally, referring to the limitations of this study such as limitations in generalizing the results to other regions and other disorders and the non-use of interviews during execution, it is recommended that future research be performed in other geographical areas and with other mental disorders.

\section{Acknowledgements:}

The cooperation of all partners, participants and patients in psychiatric clinics in Tabriz and all those who participated in this research is sincerely appreciated.

\section{References}

[1] Mohamadzadegan, Reza. (2014). Mediating role of defense mechanisms in the relationship between early maladaptive schemas, cognitive distortions between the individual and borderline personality traits. Master's thesis in General Psychology, University of Tabriz. Tabriz.

[2] Vakilee Abasaliloo, Sajjad. (2014). Forecast of alexithymia based on personality traits and attachment styles with the mediating role of cognitive emotion regulation. Master's thesis in General Psychology, University of Tabriz. Tabriz.

[3] Cavallaro, R., Cavedini, P., Mistretta, P., Bassi, T., Angelone, S. M., Ubbiali, A, et al. (2003). Basal-corticofrontal circuits in schizophrenia and obsessive-compulsive disorder: a controlled, double dissociation study. Biological Psychiatry. 54: 437-443.

[4] Conklin, C. Z., Bradley, R., Westen, D. (2006). Affect Regulation In Borderline Personality Disorder. J Nervous \& Mental Disease, 194, 69-77. 
[5] Davison, D., Neal, J., Kring, A., Johnson, S. (2007). Abnormal psychology. New York: Wiley.

[6] Dell'Osso, B., Berlin, H. A., Serati, M., Altamura, A. C. (2011). Neuropsychobiological Aspects, Comorbidity Patterns And Dimension Almodelsin Borderline Person- Ality Disorder.Neuropsychobiology, 61,169-179.

[7] Feliu-Soler, A., Carlos Pascual, J., Soler, J., Pérez, V., Armariob, A., Carrascob, J., Sanzb, A., Villamarínb, F., Borràsb , X. (2013). International Journal of Clinical and Health Psychology, 13, 9-17.

[8] Fertuck, E. A., Lenzenweger, M. F., Clarkin, J. F., Hoermann, S., Stanley, B. (2006). Executive Neurocognition, Memory Systems, And Borderline Personalitydis - Order. Clinical Psychological Reviews, 26, 346-375.

[9] Garnefski, N., Kraaij, V., \& Spinhoven, P. (2001). "Negative life events ,cognitive emotion regulation and emotional problems". Personality and Individual Differences, 30, 1311- 1327.

[10] Gratz, K. L., Tull, M. T., \& Gunderson, J. G. (2008). Preliminary data on the relationship between anxiety sensitivity and borderline personality disorder: The role of experiential avoidance. Journal of Psychiatric Research 42, 550-559.

[11] Hila, Z. Gvirts., Hagai, Harari. , Yoram, Braw ., Daphna, Shefet., Simone, G. Shamay-Tsoory ., Yechiel ,Levkovitz. (2012). Executive functioning among patients with borderline personality disorder (BPD) and their relatives. Journal of Affective Disorders, 143, 261-264.

[12] Judd, P. H. (2005). Neurocognitive Impairment Asamoderator In The Development Of Borderline Personality Disorder. Development And Psychopathology, 17, 1173-1196.

[13] Kunert, H. J., Druecke, H. W., Sass, H., Herpertz, S. C. (2003). Frontal Lobe Dysfunctions In Borderline Personality Disorder? Neuropsychological Findings. Journal Of Personality Disorders 17, 497-509.

[14] Lezak, M. D. (1995). Neuropsychological assessment. 3rd ed. New York: Oxford University Press;

[15] Lieb, K., Zanarini, M. C., Schemahl, C., Linhan, M., Bohnus, M. (2004). borderline personality disorder. lancet, 364,453-461.

[16] Mak, A. D., Lam, L. C. (2013). Neurocognitive profiles of people with borderline personality disorder. Curr Opin Psychiatry; Jan; 26(1):90-6.

[17] Marissen, M. A., Arnold, N., Franken, I. H. (2012). Anhedonia Inborderline Personality Disorder And Its Relation To Symptoms Of Impulsivity. Psychopathology, 45(3), 179-184.

[18] Naderi, N. (1994). A study of information processing and some of neuropsychological functions patient with obsessive-compulsive disorder. Tehran: psychiatry institute of Tehran.

[19] Paris, J. (2006). Borderline personality disorder what is it, what is causes it, How can we treat it. Canda Leading Medical Journal; 172(12).

[20] Paris, J., Gunderson, J., Weinberg, I. (2007). The interface between borderline personality disorder and bipolar spectrum disorders. Compr Psychiatry; 48(2): 145-54.

[21] Pfaltz, M. C., Schumacher, S., Wilhelm, F. H., Dammann, G., Seifritz, E., Martin-Soelch, C. (2015). Acoustic Emotional Processing in Patients With Borderline Personality Disorder: Hyper- or Hyporeactivity?. J Pers Disord, Feb 24:1-19

[22] Reed, L. I., Zanarini, M. C. (2011). Positive Affective And Cognitive States In Borderline Personality Disorder. Journal Of Personality Disorders, 25(6), 851-862. 
[23] Ruocco, A. C. (2005). The neuropsychology of borderline personality disorder: a metaanalysis and review. Psychiatry Research, 137, 191-202.

[24] Sanislow, C. A., Grilo, C. M., Mcglashan, T. H. (2000). Factor Analysis Of DSM-III-R Borderline Personality Disorder Criteria In Psychiatric Inpatients. Am J Psychiatry, 157, $1629-1633$.

[25] Sharp, C., Pane, H., Ha, C., Venta, A., Patel, A. B., Sturek, S., Fonagy, P. (2011). Theory Of Mind And Emotion Regulation Difficulties In Adolescents With Borderline Traits. J Am Acad Child Adolesc Psychiatry, 50(6), 563-573.

[26] Spreen, O., Strauss, E. (1991). A compendium of neuropsychological tests. Oxford University Press: New York.

[27] Sprock, J., Rader, T. J., Kendall, J. P., Yoder, C. Y. (2000). Neuropsychological FunctionIng In Patients With Borderline Personality Disorder. Journal Of Clinical Psychology 56, $1587-1600$.

[28] Winter, D., Elzinga, B., Schmahl, C. (2014). Emotions and memory in borderline personality disorder. Psychopathology;47(2):71-85. 